This is the peer reviewed version of the following article: Hersh, M. and Mouroutsou, S. (2019), Learning technology and disability-Overcoming barriers to inclusion: Evidence from a multicountry study. Br J Educ Technol, 50: 3329-3344, which has been published in final form et https://doi.org/10.1111/bjet.12737. This article may be used for non-commercial purposes in accordance with Wiley Terms and Conditions for self-archiving.

\title{
Learning Technology and Disability - Overcoming Barriers to Inclusion: Evidence from a Multi-Country Study
}

\section{Marion Hersh}

Marion Hersh is a senior lecturer/associate professor in Biomedical Engineering at the University of Glasgow. Their current research interests are in the areas of assistive technology, including inclusive learning technologies and pedagogies, and accessibility and usability of educational games, and ethics and social responsibility issues in science and engineering. They have developed frameworks for the classification and evaluation of learning technologies for disabled people and organised and chaired the first IMA Conference on Barriers and Enablers to Learning Maths. Address for correspondence: Marion Hersh, Biomedical Engineering, University of Glasgow, Glasgow G12 8LT, Scotland. Email: marion.hersh@glasgow.ac.uk

\section{Stella Mouroutsou}

Stella Mouroutsou is a lecturer in Education at the University of Stirling. She teaches on the Initial Teacher Education programme in the Faculty of Social Sciences. Her research interests lie in inclusive education and education policy. She completed her PhD in the School of Education, University of Glasgow, and her doctoral research explored policy enactment in the field of inclusive education from a complexity perspective.

\begin{abstract}
The paper uses data from a 15-country study to discuss the factors which affect the use of Information and communication technologies (ICT) learning technologies by disabled people and consequently their access to education. Significant differences were found both between and within countries: income and language were the main factors affecting availability. Thus the greatest availability was in the higher income English speaking countries and the richer European countries. The main barriers to technology use included cost, lack of funding and lack of information. A particular disparity in technology access was found between the English speaking European population and Aboriginal speakers of indigenous languages in Australia, with considerably greater access by the former than the latter group. A number of recommendations are presented to increase access to learning and assistive technologies by disabled people. They include encouragement for developers to produce free of charge (minority language) technologies, research on more effective provision of technologies and personal assistance, assistive technology centres in all learning institutions, simple funding mechanisms and a fund to support technology provision in the poorer countries.
\end{abstract}

Keywords: learning technologies, assistive technologies, inclusion, barriers, language, income, information.

\section{Introduction}

Many countries have incorporated the principles of the Education for All movement (UNESCO, 2000) into their policies and legislation. However, lack of attention to implementation, particularly accessibility, means that many disabled people still experience numerous barriers to both education and employment. The barriers to education include inaccessible or only partially accessible learning environments (WHO, 2011), limited legislation on their rights to education (Forlin \& Lian, 2008), limited financial support (Hernandez, 2006) and teachers' negative attitudes and teachers' and parents' low 
expectations (McGrew \& Evans, 2004; OPM, 2014). Disabled students are underrepresented in further and higher education (Konur, 2006) and obtain poorer degree results despite comparable entry qualifications (Fuller et al., 2004). The resulting disadvantages include reduced opportunities for personal development and reduced qualifications and combine with attitudinal and other barriers (Daone and Scott, 2003; Roberts et al., 2004) to significantly reduce employment (Barnes et al., 1998; Szeto, 2014).

In this article disability is understood in terms of the social (Barnes, 1994) rather than the medical model. Therefore, the focus is on overcoming the various barriers which disadvantage people with impairments i.e. mental or physical differences which affect the way they do things. These barriers affect both access to education and access to learning technologies.

Information and communication technologies (ICT) are increasingly used in education. Learning applications include mobile learning e.g. (Motiwalla, 2007), microlearning (Hug, 2007) and games based learning e.g. (Hersh and Leporini, 2012). ICT can reduce geographical (Mooij, 2007; Sanyal, 2001) and communication barriers (Lim \& Chai, 2004) and enhance the learning process by enabling new approaches (Sanyal, 2001). However, inappropriate uses and design which is not fully accessible and usable (Hersh and Leporini, 2012) or does not meet the needs of a wide range of disabled people can increase the digital divide, leading to further exclusion.

Accessibility is about the system input and output enabling particular (groups of) users to use all system facilities, whereas usability is about them being able to do this effectively, efficiently and with satisfaction (Federici et al. 2005). Design for all or universal design aims to ensure accessibility and usability by a wide range of users, regardless of disability, age, size, culture, ethnic background or class and without the need for adaptation or specialised design (Connell et al., 1997). This clearly has advantages, particularly as the design of many otherwise good ICT learning tools has not considered the needs of disabled learners.

There are advantages in a strict design for all approach with technologies directly accessible without the need for assistive access technologies. However, where direct accessibility would lead to complex or expensive solutions, it is preferable to modify existing learning technologies to make them accessible or use them together with assistive technologies (Day and Edwards, 1996; Edyburn, 2006), giving a need for compatibility with assistive technologies. However, modifying technologies is generally more expensive and gives a poorer result than using a design for all approach from the start (Hersh, 2010). This gives rise to a need for recommendations and principles of good practice for developing, choosing and applying ICT learning technologies (Hersh and Mouroutsou with others, 2014).

Despite considerable discussion, there is not yet general agreement on the terms and their definitions (Robyler \& Doering, 2013). The term educational technology will be used here to denote the 'processes, tools, equipment, devices and systems used to support and facilitate learning, teaching and assessment' whereas learning technology will cover 'both educational technologies and the assistive technologies used to, for instance, access educational technologies and/or learning materials, participate in learning activities and/or overcome barriers to learning' (Hersh, 2016, p. 770). Assistive technology is defined here as 'technologies, equipment, devices, apparatus, services, systems, processes and environmental modifications used by disabled and/or elderly people to overcome the social, infrastructural and other barriers to independence, full participation in society and carrying out activities safely and easily' (Hersh and Johnson, 2008, p. 196).

There are a number of case studies of the effective use of ICT learning technologies by and with disabled learners (Hersh and Mouroutsou, 2014; Bothe, 2013; UNESCO, 2011), and numerous examples of inaccessible technologies, inappropriate uses and other problems 
(Sidlay, 2014). Examples of successful initiatives include case studies of the effective use of ICT by disabled adult learners (Clay et al., 1988) and assistive technology by visually impaired students (Neumann, 2002). They include the use of a sophisticated screen magnification package and scanner to enable partially sighted students to take notes and have the documents read back using a text-speech conversion package on the laptop. Other examples of useful equipment include software to help organise ideas, speech recognition software, adapted keyboards, reader pens, scanners with OCR (optical character recognition) and 'Texthelp Read and Write' (Banes \& Seale, 2002). Additionally, Kurzweil 3000 provides a combination of scanning and text-to-voice software and is particularly useful for visually impaired and dyslexic learners (Doyle \& Robson, 2002).

However, there is a lack of data on the different ways in which learning technologies are used to support disabled students in different countries and a lack of recommendations for good practice. This research aims to fill this gap. Its specific objectives are (i) a comparative evaluation of the use of ICT learning technology with disabled learners in different countries; (ii) the identification of and production of recommendations for good practice in their use; and (iii) providing input into recommendations for the future research agenda on ICT learning technologies for disabled learners.

The paper is laid out as follows. The methodology used to obtain the data is given in section 2. The main results are presented in section 3 which is divided into three subsections. They are discussed in section 4 and conclusions and recommendations presented in section 5 .

\section{Methodology}

The data presented here was obtained by the Enable Network Project. A questionnaire was sent to project partners in the partner countries: Australia, Estonia, Finland, Germany, Greece, Indonesia, Ireland, Italy, Korea, Lithuania, Poland, Serbia, Slovakia, Slovenia and the UK (treated as one country rather than four). These project partners comprised a variety of different types of organisations, including universities, research institutes including one working on technology and disability, organisations of disabled people, a training centre and an organisation championing inclusive learning and teaching through the use of technology. All the organisations had experience of using technology to support disabled learners in lifelong learning.

These countries vary greatly on population, size, average income, income distribution, and computer and internet access (Hersh and Mouroutsou, 2014). However, significant differences in the percentages of disabled people are probably at least partially due to differences in definitions, data collection methods and diagnosis rates.

The questionnaire was divided into three sections, covering the following issues for each country:

A. ICT learning technologies available for disabled people, national legislation on avoiding discrimination and access to education, the education system, the types of ICT learning technologies for disabled people in different learning institutions, funding availability for ICT learning technologies and other support for disabled students and demographical data. Differences in different parts of the country were also considered.

B. Access to education by disabled people and the use of ICT learning technologies, particularly to support disabled people.

C. Sources of information, including partner expertise, other experts and literature consulted.

The published sources of information used are referenced in (Hersh and Mouroutsou with others, 2014). Many of them involve statistics published by city administrations or national 
governments of the partner countries or the European Commission. Analysis of the questionnaire responses was carried out by the authors of this paper to produce a report. This report produced was circulated to all the project partners for comments. The current paper was produced using further analysis and additional data to fill in some gaps. It focuses on the availability and use of ICT learning technologies in the partner countries.

Qualitative data analysis was used, as the data was largely qualitative. It followed a interpretivist thematic approach to provide a nuanced and complex understanding of the data. Reoccurring themes, relevance to existing literature and the specific research questions were used to organise the data. Thus a description of the data was followed by emerging themes and analysis, and then its broader implications, including recommendations for good practice.

\section{Results}

Information was received from all 15 partner countries. However, the quantity and precision of the available information varied greatly between countries. The results related to learning technologies are summarised in the following subsections and the supplementary material and discussed in section 4.

\subsection{The availability of learning technologies in the different partner countries}

Australia:

- There is a digital divide between ICT access in cities and rural/remote areas and between the European and indigenous populations. The digital divide in remote areas is even greater for disabled students.

- Many assistive and learning technologies are available in English (often the second or third language for indigenous students), but there are no assistive technologies in Australian indigenous languages.

- Online applications and apps for mobile phones are particularly popular and include speech-to-text conversion, screen readers and magnification software. The JAWS screenreader is popular, but the licence cost is prohibitive for many students.

- High costs, the lack of learning materials in appropriate accessible formats e.g. compatible with Daisy (Digital Accessible Information SYstem) readers, the lack of diagnosis particularly in remote areas and the lack of recognition of the need for support are the main barriers to assistive technology use

Estonia:

- There are two main types of learning technologies: (i) e-learning platforms, such as the web-based learning management system IVA developed in Estonia; and (ii) online dictionaries and handbooks (in Estonian), e.g. the Estonian dictionary of grammar ÕS and the Estonian handwriting tool SÕNAR.

- A text-to-speech converter and Thunder screen reader are available free of charge in Estonian.

- Only a small number of learning technologies are available in Estonian, though some English-language technologies are available.

Germany:

- A wide range of different types of ICT learning tools suitable for disabled people are available, both only in German and in several different languages.

- Some of the tools are subject specific, whereas others relate to skills or are assistive technologies such as screenreaders.

- Some of the systems are open source and free of charge, whereas others cost from ten to well over a thousand euros. 
Greece

- A collection of free online learning tools and technologies is available in Greek for different groups of disabled people.

- Bilingual Greek/Greek Sign Languages learning technologies are available for teaching several subjects to hearing impaired students.

- A free, but limited version of educational software products with text-to- speech conversion for visually impaired primary and secondary school students is available online, but requires completion of an application form.

- $\quad$ There are two tools to support learning Greek sign language.

Indonesia

- Most disabled people lack access to assistive, learning and other technologies.

- JAWS and other assistive technologies are available in Bhasa Indonesian.

- Few disabled people are able to afford assistive technologies, due to their high cost, low wages and very limited government support.

- The Blackberry is widely used by professionals and students and some of its features are being used to assist disabled students access learning materials.

Ireland

- A wide range of assistive and learning technologies is available in English, including screenreaders, speech text conversion software, optical character recognition software and scanning pens.

- There is some subject-specific assistive software e.g. for music.

- Some mainstream learning technologies are suitable for disabled students.

Italy

- Most ICT learning technologies for disabled people are activity specific assistive technologies. Some topic specific learning software are also available.

- Accessible learning apps and assistive technologies for mobile devices are increasingly being developed e.g. accessible and assistive-technology equipped MP3 players to read audiobooks and other documents; and subject, skill or impairment specific learning software e.g. for learning mathematics.

Korea

- A number of different types of assistive technologies are available in Korean (or Asian languages).

Lithuania

- The main ICT learning technologies for disabled people are screen readers (and optical character recognition software), tools for learning Lithuanian sign language and subject specific learning technologies in Lithuanian Sign Language.

- The well-known screen reader JAWS is available in Lithuanian, but requires an extension for Lithuanian characters to read Lithuanian texts. Screen readers are relatively expensive.

- Thunder, a free screen reader, is available, but without Lithuanian fonts. There is a free online Lithuanian voice synthesizer "garsiai.lt".

Poland

- A range of assistive and learning software is available in Polish, including Polish interfaces for the screenreaders Window-Eyes and Jaws, screen magnification and reading programmes and Braille notetakers with a speech synthesizer. 
- Polish language technologies produced in Poland and abroad may differ in price and functions: the Polish Braille notetaker Kajetek is considerably cheaper than Polish versions of imported Braille notetakers, but lacks a Braille display.

- There are both subject specific technologies for specific groups of disabled students and mainstream technologies suitable for disabled students.

- English versions of e.g. talking calculators for blind people are cheaper and therefore more popular than the Polish ones.

- Despite the existence of Polish distributors and online discussion lists, potential users often lack information about what is available.

- Quality is variable, with some technologies performing very well and others having some or numerous faults.

Serbia

- Few assistive technologies are available.

- Most assistive technologies are for visually impaired people: the most popular ICT are a screen reader using a combination of JAWS and AnReader and the Plextalk player and recorder for converting files to DAISY format.

- The main barriers to obtaining ICT are high cost, leading to a digital divide based on income, and the lack of ICT tools in Serbian. Since most disabled people are poor they have limited access to ICT.

- Internet access at $55.8 \%$ of households is lower than in many other countries.

Slovakia

- A wide range of assistive hardware and software and learning support systems is available for different groups of disabled people. This includes optical character recognition, screen magnifiers, screenreaders, Braille notetakers, Braille embossers and software for creating tactile diagrams for blind people; induction loop, infrared, radio and FM assistive listening systems for deaf people; mouse emulators and pointers controlled by head or mouth movements for physically disabled people.

- There is little subject or skill specific ICT learning technology for disabled people.

- Barriers to assistive technology use include limited availability in Slovakian, high costs with complicated procedures for obtaining funding, and little information about what is available.

- Assistive technology available in Europe can generally be purchased in Slovakia either through distributors or directly from producers.

Slovenia

- The use of assistive technology to support learning in formal education is relatively common. Available technologies include optical recognition software, screen reading and magnification software, alternative and augmentative communication systems, Braille displays, Braille notetakers and hardware and software for computer access by physically disabled students.

- Skill improvement technologies e.g. for reducing stuttering are used in special education by psychologists and speech therapists.

- Most technologies are not free. Free technologies for disabled students include online e-learning skill specific courses e.g. ceramic design, IT skills and accessible online information systems.

UK

- Several hundred learning technologies are available.

- Many of them are assistive technologies used to support particular functions, organise and/or provide access to information for different groups of disabled people. They include electronic notetaking and communication technologies for deaf people, screen magnification, screen reading, scanning, optical character recognition and Braille 
notetakers for blind people, memory, mouse emulation and pointer devices for physically disabled people, and organisation and web customisation tools for various groups.

- Over half the 150 items in the Enable data base are available in English in the UK, with half of these items available free and just over a fifth costing more than $€ 100$.

\subsection{The availability of different types of learning technologies}

The availability of different types of learning technologies in the partner countries other than Germany and the English speaking countries (which have examples of all these technologies) is summarised in table 1. More details are provided in the supplementary materials. This includes details of sources of funding in table 2.

\begin{tabular}{|c|c|c|c|c|c|c|c|c|c|c|c|}
\hline & EST & FIN & GRC & IDN & ITA & LTU & POL & PRK & SRB & SVK & SVN \\
\hline \multicolumn{12}{|l|}{$\begin{array}{l}\text { General learning } \\
\text { technologies }\end{array}$} \\
\hline $\begin{array}{l}\text { Internet LMS \& } \\
\text { environments }\end{array}$ & $x$ & $x$ & & & & $x$ & & $x$ & & & \\
\hline $\begin{array}{l}\text { Mainstream } \\
\text { learning techs }\end{array}$ & $x$ & & $X$ & & & & & $x$ & & & \\
\hline $\begin{array}{l}\text { Apps for mobile } \\
\text { devices }\end{array}$ & $x$ & & & & $X$ & $x$ & $X$ & & & & \\
\hline $\begin{array}{l}\text { Online reference } \\
\text { works }\end{array}$ & $x$ & & & & & $x$ & $\mathrm{X}$ & & & & \\
\hline \multicolumn{12}{|l|}{$\begin{array}{l}\text { Subject specific } \\
\text { learning tech }\end{array}$} \\
\hline $\begin{array}{l}\text { Subject specific } \\
\text { materials }\end{array}$ & & & $\mathrm{X}$ & & $X$ & $x$ & $\mathrm{X}$ & $x$ & & & \\
\hline $\begin{array}{l}\text { Subject specific in } \\
\text { sign }\end{array}$ & & & $\mathrm{X}$ & & & $x$ & & & & & \\
\hline $\begin{array}{l}\text { Vocational } \\
\text { training materials }\end{array}$ & & & & & & $x$ & & & & & \\
\hline \multicolumn{12}{|l|}{$\begin{array}{l}\text { Communication } \\
\text { support }\end{array}$} \\
\hline $\begin{array}{l}\text { Learning national } \\
\text { sign lang. }\end{array}$ & $x$ & & $\mathrm{X}$ & & & & & & & & \\
\hline AACS & & & & & & & $X$ & & & & $\mathrm{X}$ \\
\hline \multicolumn{12}{|l|}{ Access devices } \\
\hline Screen readers & $\mathrm{x}$ & $\mathrm{x}$ & $X$ & $X$ & $X$ & $x$ & $X$ & $x$ & $x$ & $x$ & $X$ \\
\hline Braille devices & $\mathrm{x}$ & & & & $X$ & & $\mathrm{X}$ & & & $\mathrm{x}$ & $X$ \\
\hline $\begin{array}{l}\text { Access for } \\
\text { physically } \\
\text { disabled }\end{array}$ & & & & & & $x$ & $X$ & $x$ & & $x$ & $X$ \\
\hline $\begin{array}{l}\text { Software for } \\
\text { hearing impaired }\end{array}$ & & & $\mathrm{X}$ & & & & $\mathrm{X}$ & & & & \\
\hline
\end{tabular}

Table 1 Availability of learning technologies in the partner countries

\subsection{The provision of ICT learning technologies in educational institutions in the different countries}


Many educational institutions provide computing devices and software, which may include assistive software and hardware or learning technologies which are accessible to disabled students. However, there are no standards for what should be available and some institutions expect students to provide their own computing devices. The information from the partner countries is summarised below:

Australia

- All students (school, vocational education and training and university) can access computers free of charge at their institutions, generally with greater availability at university than school level.

- Away from the institution students need to fund their own hardware and internet connections.

- Some primary schools provide laptops, but most secondary and tertiary students are expected to provide their own.

- Some universities have an assistive technology area of the library with computers with screen readers, other adapted software, ergonomic furniture, and private study rooms.

- Most universities provide free short or long term loans to students of notebook computers, digital voice recorders, spell checkers, phonic ear FM kits, MP3 players, Pearl cameras, DAISY readers and talking calculators. WYNN screen reader and Dragon speech input software can also be uploaded to students' computers.

Finland

- Secondary school students and teachers in Finland are expected to use ICT in all subjects, but the recommendations do not cover assessment.

- All Finnish schools are required to provide a high speed wireless network in the school and provide smart devices to students who do not have their own.

- Tablets are being used in teaching in several cities and several city councils provide all lower secondary school students with an ipad.

- Instead of full public funding, private-public partnerships to fund hardware and software in schools and training for teachers and students in its use is encouraged. This is likely to lead to better provision in high income areas, leading to increased disadvantage for schools in low income areas. It also moves away from the principle of education as a public good to be provided by the state through taxation.

Italy

- Primary and secondary schools in Italy are required to provide computers equipped with assistive technology for disabled students, though there does not seem to be a standard setup.

- Some universities provide computers with assistive technology.

Korea

- Modified keyboards, mouse emulators, screen magnifiers and screen readers are readily available in special education schools,

- Assistive technology for computer access is only provided in mainstream schools if required by a particular student.

- Assistive devices required by a particular student and not already available in the school can be obtained by special and mainstream teachers submitting a request to the local centre supporting special education.

- Universities provide the available technologies for visually and hearing impaired students, including Braille devices, scanners, screen magnifiers and recording devices.

Slovakia

- Schools are required to meet students' requirements for special equipment, such as learning technologies, and audio-visual equipment, but there is limited information on implementation and the resulting availability of ICT and other technologies. 
- Schools may adapt their environment to increase accessibility e.g. to buildings, classrooms and toilets and modify tables and chairs. The Centre of Special Pedagogic Counselling provides assessment and makes recommendations to schools.

Slovenia

- Some assistive technology is available in educational institutions.

- Decisions about the use of particular applications, programs and web content are generally taken by individual teachers and learners.

UK

- Computers are available free of charge to all students at all levels of education, with generally greater availability at university than school level.

- In most colleges and universities the standard software on all machines includes screen readers and possibly some additional assistive technology.

- A number of universities and colleges have an assistive technology centre in the library, which provides a range of assistive technologies, ergonomic furniture and private study rooms.

\section{Discussion}

ICT has considerable potential to provide important educational tools to support disabled learners (UNESCO, 2011). This work has explored several interrelated factors which affect the use of ICT learning technologies by disabled people in different countries. The two most important factors are language and income. These factors affect both disabled and nondisabled learners. However, as will be discussed below, they have a particular impact on non-disabled learners.

The languages in which assistive and other learning technologies are available significantly affect where they can be used. Most learning technologies are available in English (Bothe, 2013), followed by the languages of the larger European countries. Thus there are several hundred learning technologies available in the UK, Australia and Ireland, and large European countries such as Germany and Italy, but only a small number in Estonian in Estonia, though some English-language technologies are also available there. This expands on the already reported lack of availability of text-to-speech software in local languages (Raja, 2016; UNESCO, 2013). However, the existence of a well-developed IT industry in many of the Asian countries seems to be countering this tendency and has led to reasonably good availability of learning technologies in some Asian languages (UNESCO, 2014). This seems to be the case for Korea where a number of different types of assistive technologies are available. Since, as discussed in the introduction, disabled people frequently have reduced access to education, they are less likely to be particularly disadvantaged by this.

The large European partner countries, except Italy, which has a moderate income relative to the other partner countries, all have relatively high average incomes. Indonesia and Serbia, the two countries with the lowest average incomes had the poorest availability of learning technologies. The high cost of learning technologies and the lack of financial support in Serbia meant that they are only available to the richer sections of the population. This excludes most disabled people, who generally have below-average incomes (Kidd et al., 2000; WHO, 2011). The low availability of Serbian language assistive and other learning technologies also restricts them to the sections of the population with greater access to education, generally people with higher incomes. Thus disabled people rarely have access to appropriate assistive technology, leading to serious, but avoidable barriers to carrying out every day, learning and other activities. Germany which has a high average income, has a large range of learning technologies, available both just in German and in several other languages, which is probably useful for speakers of other languages living in Germany. This 
confirms the findings of other studies which show a linear relationship between income per capita and the availability of assistive technologies (G3ict, 2012). Screen readers were one of the few technologies available in all the partner countries. However, they are only available in $19 \%$ of minority languages (G3ict, 2012). In many cases local language versions of JAWS are used. Both Window-Eyes and JAWS are used in Poland and Estonia has the free Estonian language text-to-speech conversion and screen reader Thunder, which is also available in the following partner languages German, Greek Italian, English, Polish and Slovak.

The availability of information about accessible learning technologies also varied greatly between countries, with no or limited information acting as a significant barrier to technology use. In general, most information was available in English, followed by the other 'dominant' languages. Even where there are local technology distributors (and online discussion lists), potential end-users may find it difficult to obtain information about availability and the differences in features and performance of similar technologies. This is in line with reports of the limited availability of information about the use of assistive technologies (UNESCO, 2013). In addition, disabled people may have less access to information than non-disabled people (WHO, 2011).

Greater technology availability generally also leads to greater availability of open source (free) and low cost technologies. This may also lead to reductions in unit cost, as more units are sold. For instance, in Poland English language talking calculators for blind people are more popular than Polish ones, as they are considerably cheaper. Although not feasible for everyone, many people will learn the limited vocabulary required to use foreign language talking appliances such as talking calculators or scales if they are significantly cheaper. However, technologies such as screen readers (which read everything on the screen) clearly need to be in the local language. In addition, where safety is critical, the use of a foreign language version of a talking appliance could increase risk. In some cases local and imported versions of assistive technology differ in both features and price. For instance, the Polish Braille notetaker Kajetek is considerably cheaper than Polish versions of imported Braille notetakers, but lacks a Braille display.

There were also significant differences in technology availability within countries, particularly between urban and rural areas and between speakers of the majority and minority (indigenous) languages. These differences were particularly stark in Australia. A large number of assistive and other learning technologies were available in English, the main language of the European population, but none in any of the languages of the (rural) indigenous/Aboriginal people, for whom English is a second or third language. The digital divide between European origin students in urban areas and indigenous students in rural areas was further widened by low incomes and low rates of diagnosis in rural and remote areas, with diagnosis used as a gate-keeping mechanism for obtaining assistive technologies.

Other within-country barriers to accessing available learning technologies included cost and lack of funding mechanisms. Due to the relatively small number of disabled people in employment (Szeto, 2014) and frequent perceptions that disabled people are not economically productive, spending on ICT for them has rarely been prioritised. For example, a study of US students found price to be the greatest barrier to e-reader adoption (Foasberg, 2011). Assistive technology can be extremely expensive. For instance, in the UK, the home version of the JAWS screen reader costs $£ 600$ while sophisticated augmentative and alternative communication devices including eye tracking equipment cost $£ 3,000$ to $£ 10,000$ (POST, 2012). Cost was generally a greater barrier in the lower than higher income countries, due to costs generally being a higher proportion of income and funding less likely to be available and more limited when it was. 
Although only limited information about the availability of learning technologies in educational institutions in the different partner countries was available, many of them were found to have some level of provision. However, there were increasing moves to a bring your own device approach (Dennen \& Hao, 2014). This has the advantages of ensuring that each disabled learner has all the assistive technology they need already installed and can use a familiar device. This can be particularly useful, as educational institutions may lack the flexibility to take full account of student needs and preferences based on their ways of working, accessibility issues or other factors. However, it has the significant disadvantage of transferring costs from the institution to the learner. This increases disadvantages based on factors such as low income, unless sufficient funding is available to allow all learners to obtain the device(s) of their choice. In addition, educational institutions need to provide computing devices with a wider range of software and higher computing power.

In the UK and Australia, computers were available to all students free of charge at all levels of education, with much greater availability at university level. Colleges and universities in Australia and the UK generally provided screen readers and some other assistive technology on all computers and an assistive technology centre with a range of assistive technologies, ergonomic furniture and private study rooms in the library. Finland had a strategy for promoting the use of learning technologies in education. However, this raises issues of the best strategy for optimum use of learning technologies to support learning and teaching and take account of learner differences. This will require some flexibility to allow learners to use technologies in ways that support rather than disadvantage them.

Disabled people generally required funding for technology, even in the higher income countries, due to their lower than average incomes (Kidd et al, 2000; WHO, 2011). Public funding of assistive and learning technologies for disabled people also contributes to acknowledging society's responsibility for overcoming the barriers they experience, including to participating in education. A variety of different, generally public, sources of funding were used, including national and local government, education and employment ministries, local education authorities and social services (see supplementary material) (G3ict, 2012). Other sources included health insurance providers and a variety of special programmes and rehabilitation funds, sometimes funded by governments. The fact that national health services, health insurance and/or social services rather than education ministries funded learning (or employment support) technologies in several countries may indicate that disabled people are frequently treated as patients rather than citizens requiring support to overcome barriers.

In Serbia non-governmental organisations were the main source of funding through specific projects for assistive technology. This resulted in low levels of uneven funding. In countries such as Slovakia complicated procedures for obtaining funding acted as further barriers. In general, the availability of funding for the additional requirements of disabled learners depended largely on (i) the priority given to education of disabled people; and (ii) the country's wealth or poverty. Some of the poorer partner countries, such as Serbia, probably require financial support from outside the country to adequately support disabled learners. However, many of the partner countries are in a position to finance considerably better educational provision for disabled learners, but do not prioritise this.

The results indicate that there is better provision of learning technologies for people with sensory impairments, particularly blind people. This gives rise to a need to investigate the reasons for this and any gaps in provision and need to develop additional technologies for other groups of disabled people. Thus the results presented here confirm existing research on several issues, including the lack of text-to-speech software in local languages (Raja, 2016; UNESCO, 2013), the relationship between assistive technology availability and income (G3ict, 2012), the lack of availability of information about assistive technologies for disabled people (UNESCO, 2013) and moves to 'bring your own device' (Dennen \& Hao, 2014). They also go beyond existing research, both by covering additional topics and 
through the provision of additional details. Additional topics include the dependence of assistive and learning technology availability on language and the interaction between language and income in determining access to learning technologies. Further new topics raised are the within-country factors that lead to differences in access and the differences in funding, with regards to both available funding sources and what can be funded.

Potential solutions are provided in the recommendations in Section 5 . Some of the recommendations, such as reductions in staff: students ratios, will have benefits for all students. This is of value in itself and will increase the likelihood of implementation. In addition, disabled learners' accessibility requirements mean that they are likely to experience particular benefits. The recommendations for good practice and further research are also contributions of this work. The main study limitations were difficulties in obtaining comparable information from the different countries, due in part to the lack of publicly available information in several countries.

\section{Recommendations}

The discussion above shows that, despite some progress in the use of ICT learning technologies to support the educational inclusion of disabled people, there is still a significant digital divide which affects their participation in educational and restricts their future opportunities. The following recommendations for good practice and further research have been derived from the study data and subsequent discussion with the Enable Project partners. They indicate potential solutions to the disadvantages in access to technology experienced by disabled people and highlighted in the paper.

Data

1. Regularly collecting and publicly displaying data on the participation rates of disabled (and non-disabled) people in mainstream and special education and employment and their qualifications.

Personal assistance

2. Developing and implementing effective strategies for providing quality personal assistance, including sign language interpretation, at a reasonable cost.

3. Measures to ensure all disabled students receive their entitlements to assistance.

4. Reducing student:teacher ratios in mainstream schools by (i) smaller classes, (ii) additional teachers in classes and/or (iii) part or full time teaching assistants for individual or small groups of disabled students.

Technology development

5. Encouraging developers to develop minority language versions of assistive and other learning technologies and provide some open source/cost-free versions of these technologies.

6. Research, drawing on classification and evaluation frameworks (Hersh, 2014, 2016) to identify gaps in technology provision and the need for new or modified assistive and other learning technologies.

Technology

7. Research on strategies to promote the effective use of assistive and other learning technologies, which consider the different needs of different (disabled) learners.

8. Research to investigate the reasons for there generally being more assistive technology for people with sensory impairments, particularly blind people.

9. The provision of a basic package of assistive and other learning technologies, including screen readers, on all computers and laptops in education and training organisations. 
10. The provision of a assistive/learning technology centre for disabled people with a wide range of assistive and other learning technologies, ergonomic furniture and quiet rooms in institutional libraries.

11. The availability of assistive and learning hardware and software that can be booked for short to extended periods free of charge.

12. Availability of technical support from well-qualified personnel for at least 12 hours each day.

Funding

12. Funding provision by national and local governments.

13. Equal entitlements to funding for part-time disabled students and informal learners

14. Simple application procedures with few exclusions and removal of upper limits on the number of students/learners who can be supported.

15. The establishment and contribution to a fund by governments of richer countries, including in EU, to support the provision of assistive and other learning technologies in lower income countries.

\section{Statements on open data, ethics and conflict of interest}

Additional data can be found at http://web.eng.gla.ac.uk/assistive/media/D3.6.pdf and all the project deliverables can be found at http://web.eng.gla.ac.uk/assistive/pages/inclusive-

learning-conference/enable-deliverables.php. However, the raw data is no longer available.

Ethical Approval was not required as all data was obtained from project partners.

There are no conflicts of interest.

Acknowledgements: To the partners in the Enable Network, the European Commission, which is not responsible for any use made of the results, and the anonymous reviewers for their helpful comments.

\section{References}

Banes, D., \& Seale, J. (2002). Accessibility and inclusivity in further and higher education: an overview. In L. Phipps, A. Sutherland, \& J. Seale, (Eds.), Access all areas: disability, technology and learning,York, UK, TechDis with the Association for Learning Technology. Oxford and York, ALT/TechDis.

Barnes, C. (1994), Disabled People in Britain and Discrimination: a case for antidiscrimination legislation, London, Hurst \& Co.

Barnes, H., Thornton, P., \& Maynard Campbell, S. (1998). Disabled People and Employment: a review of research and development work, York: York Publishing Services.

Bothe, H.H. (2013). Case studies. http://web.eng.gla.ac.uk/assistive/media/D23_Report_final.pdf Accessed 07.07.2017.

Clay, J., Cooke, B., Jotham, D, et al. (1988) Microcomputer Software NewLink with Computers, British Journal of Special Education, 15 (2), 73-75.

Connell, B.R., Jones, M., Mace, R., et al., (1997). 7 principles of universal design. http://www.extension.org/pages/24186/7-principles-of-universal-design\#.VSSg0eGzeE8 Accessed 11 September 2017.

Daone, L., and Scott, R. (2003) Ready, willing, and disabled: survey of UK employers. London, Scope, https://www.scope.org.uk/Scope/media/Images/Publication\%20Directory/Ready-willingand-disabled.pdf?ext=.pdf Accessed 11 September 2017. 
Day, S.L., \& Edwards, B. D. (1996). Assistive technology for postsecondary students with learning disabilities. Journal of Learning Disability, 29(5), 486-492.

Dennen, V. P. \& Hao S. (2014) Intentionally mobile pedagogy: the M-COPE framework for mobile learning in higher education, Technology, Pedagogy and Education, 23:3, 397-419.

Doyle, C., \& Robson, K. (2002) Accessible Curricula, Good Practice for All, UWIC Press.

Edyburn, D.L. (2006). Assistive technology and mild disabilities. Special Ed. Technology Practice, 8(4), 18-28.

Federici, S., Micangeli, A., Ruspantini, I. et al. (2005). Checking an integrated model of web accessibility and usability evaluation for disabled people. Disability and Rehabilitation, 27(13), 781-790.

Foasberg, N.M. (2011) Adoption of e-book readers among college students: a survey. Information Technology and Library, 30(3), 108-128.

Forlin C., \& Lian, M. G. J., (2008). Reform, inclusion and teacher education: toward a new era of special education in the Asia Pacific Region. London, Routledge.

Fuller, M., Bradley, A., \& Healey, M. (2004). Incorporating disabled students within an inclusive higher education environment. Disability \& Society, 19(5), 455-468.

Global Initiative for Inclusive Information and Communication Technologies (G3ict) (2012) Convention on the Rights of Persons with Disabilities 2012 ICT Accessibility Progress Report.

http://g3ict.org/resource_center/publications_and_reports/p/productCategory_whitepaper s/subCat_0/id_244 Accessed 2 September 2017.

Hernandez G. (2006). Assessing El Salvador's capacity for creating inclusive educational opportunities for students with disabilities using a capacity assessment framework. College Park, University of Maryland.

Hersh, M.A. (2010). The design and evaluation of assistive technology products and devices part 1: design, International Encyclopedia of Rehabilitation. http://cirrie.buffalo.edu/ encyclopedia/en/article/309/ Accessed 7 July 2017.

Hersh, M.A. (2016). Classification framework for ICT-based learning technologies for disabled people, BJET, 48(3), pp.768-788.

Hersh, M.A. \& Johnson, M.A. (2008). On modelling assistive technology systems- Part I: modelling framework. Technology \& Disability, 20(3), 193-215.

Hersh, M.A., \& Leporini. B. (2012). Accessibility and usability of educational games for disabled students. In Gonzalez, C. (Eds.), Student Usability in Educational Software and Games (pp. 1-40). IGI Global.

Hersh, M.A., \& Mouroutsou, S. (2014). Enable D3.4: ICT to support learning by disabled adults: fundamental principles of good practice. http://web.eng.gla.ac.uk/assistive/media/D3.4-11pt.pdf Accessed 07.07.2017.

Hersh, M.A. and Mouroutsou, S. with Astrauskiene, J, Ball S., Efthimiou, E., Evans, S., Galajdova, A, Hulist, A., Istenic Starčič, A.. Korhonen. R., Lebenicnik M., Lee, L, Leporini, B, Lepp U. Loid, E. Masłowski, P. Metsärinne, M. Mountford, H. Pasterny, H., Rajovic, V.,Šimšik, D., Słapik A. Wallbruch, R. (2014). Enable Deliverable 3.6: A comparative evaluation of ICT to support lifelong learning by disabled people in 15 different countries. http://web.eng.gla.ac.uk/assistive/media/D3.6.pdf, Accessed 11 September 2017.

Hug, T. (2007). Didactics of Microlearning: Concepts, Discourses and Examples. Waxmann Verlag.

Kidd, M.P., Sloane, P.J., and Ferko, I. (2000). Disability and the labour market: an analysis of British males. Journal of Health Economics, 19, 961-981.

Konur, O. (2006) Teaching Disabled Students in Higher Education. Teaching in Higher Education, 11(3), 351-363.

Lim, C.P., \& Chai, C.S. (2004). An activity-theoretical approach to research of ICT integration in Singapore schools: Orienting activities and learner autonomy', Computers \& Education, 43 (3), 215-236. 
McGrew, K.S., \& Evans, J. (2004). Expectations for students with cognitive disabilities: Is the cup half empty or half full? Can the cup flow over? (Synthesis Report 55). Minneapolis, MN: University of Minnesota, National Center on Educational Outcomes.

Mooij, T. (2007). Design of educational and ICT conditions to integrate differences in learning: Contextual learning theory and a first transformation step in early education. Computers in Human Behaviour, 23(3), 1499-1530.

Motiwalla, L.F. (2007). Mobile learning: a framework and evaluation, Computers \& Education, 49(3), 581-596.

Neumann, Z. (2002). Visual impairments and technology. In L. Phipps, A. Sutherland, \& J. Seale (Eds.), Access all areas: disability, technology and learning,York, UK (pp. 1618). TechDis with the Association for Learning Technology.

OPM (2014). Removing barriers, raising disabled people's living standards https://www.opm.co.uk/wp-content/uploads/2014/05/Removing-barriers-raising-livingstandards.pdf Accessed 11 September 2017.

Parliamentary Office of Science and Technology (POST) (2012). ICT for Disabled People. http://researchbriefings.parliament.uk/ResearchBriefing/Summary/POST-PN-411 Accessed 11 September 2017.

Raja, D.S. (2016) Bridging the disability divide through digital technologies http://pubdocs.worldbank.org/en/123481461249337484/WDR16-BP-Bridging-theDisability-Divide-through-Digital-Technology-RAJA.pdf Accessed 18 February 2018.

Roberts, S., Heaver, C., Hill, K., et al. (2004) Disability in the workplace: employers' and service providers' responses to the Disability Discrimination Act in 2003 and preparation for 2004 changes. London, Department of Work and Pensions Research Summary.

Robyler, M.D., \& Doering, A.H. (2013) Integrating Educational Technology Into Teaching (6th ed.). Boston, MA: Pearson.

Sanyal, B.C. (2001). New functions of higher education and ICT to achieve education for all', Paper prepared for the Expert Roundtable on University and Technology-for- Literacy and Education Partnership in Developing Countries, International Institute for Educational Planning, UNESCO, September 10 to 12, Paris. http://bern.library.nenu.edu.cn/upload/soft/0-article/030/30020.pdf Accessed 11 September 2017.

Sidlay (2014). The Use of Inaccessible Technology by Educational Institutions http://www.sidley.com/news/the-use-of-inaccessible-technology-by-educationalinstitutions-07-15-2014 Accessed 11 September 2017.

Szeto, A.Y.J. (2014). Assistive Technology and Rehabilitation Engineering. In (Eds), Assistive Technologies: Concepts, Methodologies, Tools, and Applications. (pp 277331). Hershey, PA : Information Science Reference.

UNESCO (2000). Dakar framework for Action, Education for all Meeting our Collective Commitments $2000 \quad \mathrm{http} / / /$ unesdoc.unesco.org/images/0012/001211/121147e.pdf Accessed 11 September 2017.

UNESCO (2011). ICTs in education for people with disabilities: Review of innovative practice https://www.european-agency.org/sites/default/files/ICTs-in-Education-for-people-withdisabilities.pdf Accessed 11 September 2017.

UNESCO (2013) UNESCO Global Report Opening New Avenues for Empowerment, ICTs to Access Information and Knowledge for Persons with Disabilities http://unesdoc.unesco.org/images/0021/002197/219767e.pdf Accessed 18 February 2018

UNESCO (2014). Information and Communication technology (ICT) in Education in Asia: A comparative analysis of ICT integration and e-readiness in schools across Asia. http://uis.unesco.org/sites/default/files/documents/information-communicationtechnologies-education-asia-ict-integration-e-readiness-schools-2014-en_0.pdf Accessed 13 February 2018

World Health Organization (WHO) (2011). World Report on Disability http://www.who.int/disabilities/world_report/2011/en/ Accessed 11 September 2017. 


\section{Supplementary Material}

\section{Questionnaire}

The paper only reports the results from this questionnaire in the following areas: the availability of ICT learning technologies in the different partner countries; the availability of different types of learning technologies; and the provision of ICT learning technologies in educational institutions in the different countries. Results on the funding of ICT learning technologies in the different partner countries and additional details on the availability of different types of learning technologies are reported later in this supplementary material.

\section{A Current Situation in your Country}

Note: Question 7 deals with differences in different parts of your country, so that in questions 1-6 you should consider the situation in the largest part of your country.

1. Please list the ICT learning technologies or tools for disabled students available in your country. For each technology please:

(a) Provide a one or two sentence description

(b) Indicate whether or not the technology is available in the national language(s)

(c) Your evaluation of how easy it is to obtain this technology.

(d) If you consider it is not easy to obtain this technology, a indication of the main barriers

e.g. cost, lack of information.

2. Please provide the main national legislation for your country in the following areas affecting disabled people:

(a) Anti-discrimination

(b) Access to education

(c) Access to and/or accessibility of technology

(d) Any other legislation that could affect the use of ICT learning technologies by disabled adults.

In each area please provide the following:

(i) Name of the legislation in your language and English

(ii) Date the legislation was passed

(iii) A brief summary (one paragraph) of the main measures in the legislation.

(iv) A brief description of how the legislation is enforced.

(v) Your evaluation of how effective the legislation is.

3. Provide brief information on the education system in your country, including the following:

(a) Policies and practice with regards to 'special'/segregated and mainstream education for disabled people.

(b) The main types or levels of education available with a brief explanation.

(c) How different types of education are funded and whether or not they are free to students.

(d) Decision making on curricula at the different levels e.g. is there a national curriculum for school education.

(e) What pedagogies ${ }^{1}$, if any, are in general use in education in your country. If appropriate indicate which levels or types of education they are used in. Are you aware of pedagogical assumptions which act as barriers to learning by disabled students? Notes:

1. Different approaches to teaching. Examples include critical, constructivist, feminist, institutional and archetypal pedagogies and there are many others.

2. funding is considered in question 5 . 
4. Provide information on the types of ICT learning technologies for disabled learners available in:

(a) Universities

(b) Adult learning centres

(c) Further education and vocational education colleges or centres.

(d) School education for students over 16

(e) Training centres for adults.

(f) Workplaces, if this information is available. It may be useful to provide some examples of good practice and indicate what the general situation is.

(g) Hospitals, clinics and other therapeutic centres, if this information is available. It may be useful to provide some examples of good practice and indicate what the general situation is.

(h) Other (please specify).

5(i) Provide a brief explanation of how ICT learning technologies for individual disabled people are funded for:

(a) University students

(b) Students in further or vocational education

(c) School students over 16

(d) Learners involved in distance or adult eduction courses leading to qualifications.

(e) Other disabled learners over 16.

(ii) Provide details of any additional funding available specifically to disabled students in the above educational sectors.

6. Provide the following statistical data:

(a) Country population

(b) Percentage of disabled people in following age groups:

(i) Under 16

(ii) 16 - 60

(ii) Over 60

(c) The percentage of disabled people in the following types of education

(a) School, including the approximate distribution between mainstream and special/segregated education.

(b) Further or vocational education

(c) University

(d) Adult and continuing education

(e) Other

(d) If possible, please provide data under (b) and (c) for disabled people with different impairments e.g. blind people and wheelchair users.

7. If your country has any semi-autonomous regions, devolved nations or local areas with differences in legislation, education system or other factors:

(a) List these semi-autonomous areas

(b) For each area,

(i) If relevant, provide the names of any local languages spoken by a significant proportion of the population

(ii) Indicate any differences in the availability of ICT learning technologies and, if relevant, whether they are available in the local language(s).

(iii) Relevant legislation which differs from the rest of the country, with details as in question 2.

(iv) Details of the education system if it differs from that in the rest of the country, with details as in question 5

(v) Statistical data on the involvement of disabled people in education, with details as in question 6. 


\section{B Situation Evaluation and Recommendations}

1. Provide a brief evaluation of the situation in your country with regards to:

(a) Ease of access to education for the non-disabled population.

(b) Representation of disabled people in education (compared to the non-disabled population).

(c) Any additional difficulties or barriers faced by disabled people in accessing education.

(d) Any enablers or good practice in access to education for disabled people.

(d) The availability of ICT learning technologies for disabled people

(e) Barriers, enablers and other factors that affect access to ICT learning technologies for disabled people.

(f) Any other comments

2. In the context of ICT learning technologies for disabled people, please explain what you understand by the following terms:

(a) Good practice

(b) Satisfactory practice

(c) Poor practice

(d) Bad Practice

3. Provide a number of examples of each of the following practices in the use of ICT learning technologies for disabled people in your country.

(a) Good practice. For each example, please explain what factors make the practice 'good'.

(b) Satisfactory practice. For each example, please explain what factors make the practice 'satisfactory'.

(c) Poor practice. For each example, please explain what factors make the practice 'poor'.

(d) Bad practice. For each example, please explain what factors make the practice 'bad'.

4. Provide suggestions for recommendations to improve

(a). The access of disabled people over 16 to education

(b) The availability of ICT learning technologies for disabled people

Please indicate whether these recommendations

(i) Relate specifically to the situation in your country.

(ii) Are more general.

5. Please provide any other comments or suggestions on the use of ICT learning technologies with disabled adults.

\section{Sources of Information}

1. Please provide:

(a) A brief of the relevant expertise of all partners involved in answering this questionnaire.

(b) Other experts, including disabled students, consulted with a brief summary of their expertise.

(c) Full citations for the literature consulted, including journal and conference papers, web sites and books.

(d) Any other sources of information used. 


\section{Results}

\section{The availability of different types of learning technologies}

General learning technologies:

1. Internet based learning management systems and multi-media learning environments: Estonia, Finland, Korea, Lithuania

2. Mainstream learning technologies which can be used by disabled people: Estonia, Greece, Korea.

3. Apps for mobile phones and other mobile devices, including speech to text conversion, screen readers and screen magnifiers and AT equipped MP3 players to read audio books and other documents: Estonia, Italy, Lithuania, Poland

4. Online reference works, such as dictionaries: Estonia, Lithuania, Poland

Subject specific learning technologies:

5. Subject specific materials (for particular disabled students): Greece, Italy, Korea, Lithuania, Poland

6. Subject specific learning materials in national sign languages: Greece, Lithuania

7. Vocational training materials (for particular groups of disabled students): Lithuania

Communication support:

8. Tools for learning national sign languages: Estonia, Greece

9. Alternative and augmentative communication systems: Poland, Slovenia

Access devices:

10. Screen readers, including JAWS and its local language versions, screen magnifiers and text to speech conversion programs: all the partner countries

11. Braille notetakers, displays and embossers (printers) for blind people: Estonia, Lithuania, Poland, Slovakia, Slovenia

12. Access devices for physically disabled people, including on-screen and large keyboards, mouse emulators and pointers: Korea, Lithuania, Poland, Slovakia, Slovenia

13. Speech to text conversion, notetaking and subtitling software for hearing impaired people: Greece, Poland

\section{The Funding of ICT Learning Technologies in the Different Partner Countries}

Access to assistive and other learning technologies by disabled people is often dependent on the availability of funding. There is considerable variation across the partner countries in the extent to which funding is available and the mechanisms used to provide it, and frequently also different mechanisms for students at different levels of education. In general, funding is targeted at students in formal full time education leading to qualifications and there is much less support for students on part time or adult and continuing education courses, and even less for those learning outside educational institutions. In many countries the funding system is complicated. For instance, in Australia it involves co-operation between the education departments of the Australian Government and the States and Territories, a plethora of allocations, grants and supplements, and specific state funding for disabled people. Most universities and larger colleges in several of the partner countries, including Australia, Korea and the UK, have a support centre for disabled students, which is responsible for providing assessments and ensuring that disabled students have the support they require, including by helping them to apply for the relevant funding for equipment or personal assistance. 
In Australia, Germany, Ireland, Italy, Slovakia and the UK the full costs of equipment for disabled students can be covered, whereas in Estonia students are required to pay $10 \%$ of the costs of assistive technology and in Poland the funding provided depends on the type of equipment and family income. The available funding may also change over time. For instance disabled students in the UK are now expected to pay £200 towards the cost of a laptop, which could act as a barrier. Available funding does not always meet the need. For instance, disabled people in Slovenia are asking for additional funding for ICT and the Student II programme of the National Rehabilitation Fund in Poland only has funding to support 14 thousand disabled students. In Serbia very limited public funding is available for the assistive technology and other support needs of disabled students. Educational institutions in Serbia are largely dependent on support from non-governmental organisations through projects to provide additional equipment for disabled students and individual students are dependent on a combination of their own resources and those of such organisations.

Funding for specific technologies and support can either be provided directly to students or through institutions, either as part of their general funding or as a specific funding allocation for support for disabled students. In some countries students or their families are expected to make a contribution, though it should not be assumed that families will necessarily do this. Several countries provide both types of financial support. The types of support which are funded for individual disabled students include the following, with some of the partners countries which provide this type of support listed after the item:

Assistance provided by a person:

- Sign language interpreters: Estonia, Lithuania, Poland (in universities), UK

- Personal assistance: Australia (in schools), Estonia, Germany, Slovenia, UK

- Additional teaching assistance or teachers: Ireland, Poland, Slovenia, UK

Technology and materials

- Assistive technology: Australia, Estonia ( $90 \%$ of costs), Germany, Poland, Slovakia, Slovenia, UK

- Other adaptations to support the use of learning technologies: Germany

- PCs, other computing devices and learning technologies: Australia, Slovakia, Slovenia, UK

- Teaching materials, including accessible electronic books: Australia, Italy

- Production of digital or other accessible versions of learning materials: Australia, Estonia, Poland, Slovenia

Other:

- Travel to educational institution: Estonia, Lithuania, Poland, Slovenia, UK

- Accommodation: Lithuania, Poland

- Fees for weekend courses: Poland

- Rehabilitation: Lithuania, Poland

- Adaptation to premises to remove access barriers: Lithuania, Slovakia, UK

\begin{tabular}{|l|l|l|l|l|l|l|l|l|l|l|l|l|l|l|l|}
\hline & AU & DE & EE & EL & FI & ID & IE & IT & LT & PL & RK & RS & SI & SK & UK \\
\hline Assistance by a person & \multicolumn{10}{|c|}{} \\
\hline Sign language interpreter & & & $\mathrm{x}$ & & & & & & $\mathrm{x}$ & $\mathrm{x}$ & & & & & $\mathrm{x}$ \\
\hline Personal assistance & $\mathrm{x}$ & & $\mathrm{x}$ & & & & & & & & & & $\mathrm{x}$ & & $\mathrm{x}$ \\
\hline Additional teacher & & & & & & & $\mathrm{x}$ & & & $\mathrm{x}$ & & & $\mathrm{x}$ & & $\mathrm{x}$ \\
\hline Technology \& materials & \multicolumn{1}{|c|}{} \\
\hline Assistive technology & $\mathrm{x}$ & $\mathrm{X}$ & $\mathrm{x}$ & & & & & & & $\mathrm{x}$ & & & $\mathrm{x}$ & & $\mathrm{x}$ \\
\hline Other adaptations & & $\mathrm{X}$ & & & & & & & & & & & & & \\
\hline Computing devices & $\mathrm{x}$ & & & & & & & & & & & & $\mathrm{x}$ & $\mathrm{x}$ & $\mathrm{x}$ \\
\hline
\end{tabular}




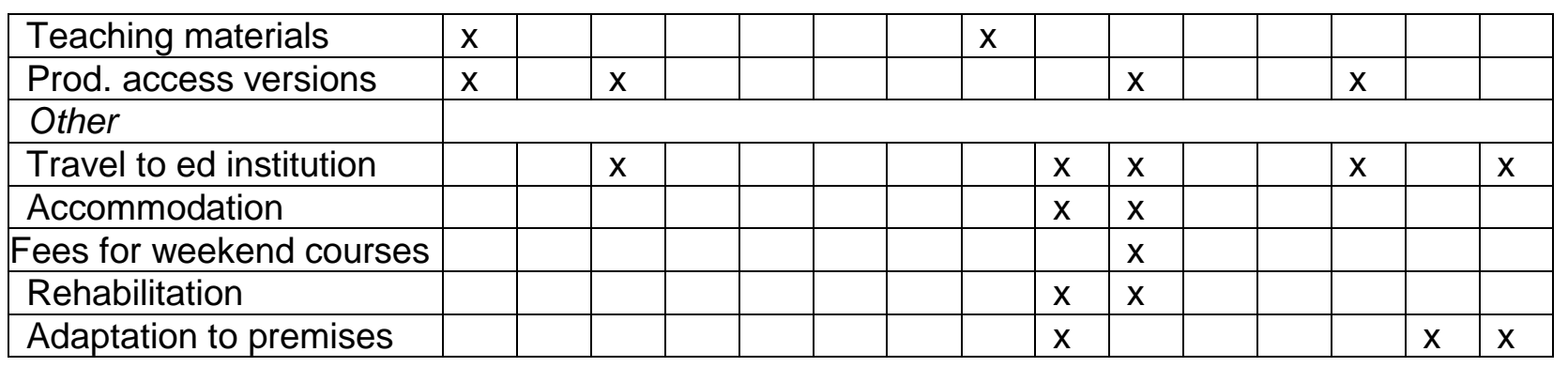

Table 2 Availability of funding for different types of support for disabled students

A variety of different types of organisations are involved in providing funding, in some countries with differences at the different levels of education. The organisations include health services and health insurance providers and social work departments, as well as education departments.

Australia

- The central/national and/or state government provides direct funding to schools and universities for support for disabled students.

- Special programmes and rehabilitation funds such as the Disability Support Pension and Mobility Allowance are available to those aged 16 years or above.

Estonia

- The PRIMUS Programme funds regular support services, such as sign language interpreters, personal assistances and transport, and repeated one-off services such as computerisation of learning materials.

- Local government covers the cost of facilities such as transport and personal assistants.

Germany

- Assistive technology and other adaptations to use ICT for work, continued education or in primary, secondary or higher education are generally funded for disabled people.

- Common teaching and learning aids such as books and personal computers for personal use are not generally funded.

- Technical aids which are for general use by a number of students in a school rather than for individual use could be funded by the local authority the school is situated in.

- Technical aids for inclusion in work or further education are funded by the federal agency for labour.

- Health insurance providers fund technical aids for individual use.

- The German Social Accident Insurance funds technical aids for individual use in the case of impairments caused by an accident.

Ireland

- The National Council for Special Education (NCSE) funds disabled students with a diagnosis up to the age of 18.

- Funding for equipment is requested by a disabled child's special education teacher an/or the school, If approved, the cost can be reclaimed from the NCSE.

- The institution funds support for tertiary level disabled students. Applications from disabled students are overseen by the institution's disability support office, with support requirements being considered as part of the process.

- Provision for disabled students in further education depends on the course and institution. 
- The Health Services Executive provides health and daily living supports free of charge. The distinction between these and educational aids is not always clear, particularly for disabled students studying away from home.

Italy

- The National Health System provides assistive technology, teaching materials and special equipment disabled children and adults free of charge.

- Students are entitled to have text books in their preferred accessible format, but there is limited information about how this is implemented in practice.

Korea

- The City Council funds assistive technology for special schools and special classes in mainstream schools.

- University centres for supporting disabled students cover the costs of new devices that the require.

- Assistive technology support centres provide assistive technology rather than funding to tertiary education institutions.

Lithuania

- Blind screen reader users are entitled to reimbursement of the cost of the screenreader JAWS.

- A Lithuanian synthetic voice and several tools for learning Lithuanian Sign Language are available free online.

- The ministry of education provides funding in vocational training.

Poland

- The Student II programme of the National Rehabilitation Fund can fund special equipment, rehabilitation, accommodation, travel to university and the fees for weekend courses for university. Funding is limited to 14 thousand students.

- Disabled learners over 16 outside formal education can apply to the Social Care Centre in their town. The funding received generally depends on the family income and the type of equipment.

- The Ministry of education offers additional teachers in integrated classes.

Serbia

- Non-governmental organisations provide most of the funding for assistive technology through projects.

Slovakia

- Equipment for disabled university students is available from European projects and a special section of the budget. Applications can be made by the student or the institution.

- Disabled students over 16 in further or vocational educational can apply to the government each year for funding for equipment and other additional needs.

- Some funding is also available from charities and firms.

- Schools have limited budgets to provide support, but can ask the Ministry of Education for additional funding.

- The Ministry of Education funds equipment and adaptations of the school environment via town councils and regional offices of the Fund for Support of Students with Disabilities at universities. This support is available to overseas students studying in Slovakia.

- Direct payment can be used to purchase devices if they are also used outside the school and support wider inclusion not just education. The student's family has to make a contribution. 
Slovenia

- Part of the budget for special schools is allocated for obtaining assistive technology.

- Sometimes mainstream schools allocate part of their budget for obtaining needed assistive technology, but frequently other financial resources are used, such as donations and finance from disability or student organisations or the town council.

- The national and/or state governments provide additional funding to disabled students in upper secondary and tertiary education who receive a government scholarship and 85$100 \%$ funding for ICT for students with sensory impairments. They also directly fund the education of disabled students in public schools and universities.

- Non-governmental disability and student organisations provide additional funding for equipment in schools.

UK

- Local Authority Children's Services fund equipment and support for disabled school children.

- In addition in some areas funding is available from Children's Trusts, as well as Social Services in England and Wales, Social Work Departments in Scotland and Health and Social Services Boards or Trusts in Northern Ireland.

- Schools often receive funding for specialist equipment for a specific student, but the equipment or technology can be shared.

- The College or Skills Funding Agency (SFA) and the College fund equipment for disabled further education (FE) students.

- FE colleges in England and Wales receive government funding for the costs of providing assistive technology and additional support to disabled students.

- The levels of support and expertise in FE colleges and universities are very variable from pockets of excellent practice with high levels of support and expertise to an hoc situation.

- When colleges bring in external trainers due to needing expertise on very specialised equipment or a general lack of AT expertise, they have to pay them from the general college budget.

- Many universities have a specialised unit for supporting disabled students, but support is sometimes spread over several roles in different departments.

- Equipment, non-medical helpers and travel costs are funded by the Disabled Students Allowance. University, but not college students can retain their assistive technologies when they leave the institution. However, disabled students now have to pay £200 to the cost of a laptop.

\section{Additional Recommendations}

Legislation

1. More widely available information on legislation giving rights to disabled people and prohibiting discrimination.

2. More effective implementation of the legislation and compliance monitoring, as well as significant sanctions for non-compliance and an adequately funded organisation with real powers to oversee implementation.

3. Research to compare the impacts of different types of legislation and legislation and other mechanisms. 


\section{Structured Practitioner Notes}

What is already known about this topic:

- Disabled students are underreprested in further and higher education and have poorer degree results despite similar entry qualifications.

- Information and communication technologies (ICT) has great potential to support disabled learners, but inappropriate design and use can lead to exclusion.

- There are several case studies of effective use of ICT by and with disabled learners and many examples of inaccessible technologies, inappropriate uses and other problems.

- Limited knowledge of the factors that affect successful use of ICT in the education of disabled people internationally.

What this paper adds:

- Income and language are the two main factors which affect ICT use by disabled people in different countries.

- In-country barriers to accessing available information technologies include cost, lack of funding mechanisms and lack of information about available technologies.

- The presentation of recommendations for good practice on designing and implementing ICT learning technologies for disabled people and further research.

- There is still a significant digital divide which affects the full educational inclusion of disabled learners and restricts their future opportunities.

Implications for practice and/or policy:

- Informing policy, including determining the future research agenda.

- Identifying ways to develop accessible ICT and use it more effectively in education to overcome barriers and develop more inclusive learning environments.

- Identification and application of measures to overcome barriers to accessing ICT learning technologies.

- The need of funding for learning technologies (for disabled learners) by national and local governments.

- The need to encourage developers to develop minority language versions of assistive and other learning technologies. 